\title{
UN TESTIMONIO DESCONOCIDO DEL DEAN MARTI SOBRE EL PANTANO DE TIBI
}

\section{Por Enrique GIMENEZ}

Universidad de Alicante

La transformación del secano en regadío es, como se sabe, la modificación básica del paisaje agrario y el único elemento que, en las economías del Antiguo Régimen, hace posible un incremento de la productividad agraria.

La posesión y explotación del agua y el sistema de riego alcanzan una extraordinaria importancia en aquellas zonas de pluviosidad escasa y elevados índices de aridez, pero en las que las condiciones térmicas y edafológicas son aptas para el cultivo. Este es el caso del entorno rural de la ciudad de Alicante, en particular la llanura situada al N. E. del perímetro urbano y conocida con el nombre, un tanto pretencioso, de La Huerta, surcada por un pequeño río, el Monnegre, de muy reducido curso y sometido a prolongados estiajes. La explotación de su escaso e irregular caudal motivó una minucionsa reglamentación sobre la propiedad y usufructo del agua, iniciada en el siglo XIII por Alfonso X el Sabio, quien donó todas las aguas que corrieran por el cauce del río a los pobladores de Alicante (1).

Con posterioridad, el agua se dividió en 336 hilos. Esta agua procedía tanto de la lluvia como de los manantiales existentes en las vertientes del río

(1) Vicente MARTINEZ MORELLA: Privilegios de Alfonso X a Alicante, Alicante 1951, p. 9. 
en los términos de Castalla, Onil y Tibi, y cuyo aprovechamiento era exclusivo de los pobladores de Alicante. El usufructo de esas aguas, procedentes de los manantiales de Mirabuenos, Ojales de Onil, Torresella y fuente del Sabe (2), provocó frecuentes conflictos entre los huertanos y los agricultores de aquellos municipios. Cada hilo suponía el derecho de riego durante hora y media, y la reunión de los 336 hilos era conocida como tanda o martava (3).

Lo irregular del caudal, los largos estiajes y la pérdida de las aguas de avenida plantearon a la ciudad la posibilidad de construir un embalse en el término de Tibi. En el último cuarto del siglo XVI se iniciaron las gestiones, elevándose solicitudes a Felipe II para que permitiera las obras y apoyara la construcción. Armando Alberola ha documentado que la traza del pantano se debió a Joan Izquierdo, cantero y vecino de Alicante (4), iniciándose los trabajos en 1580 y finalizándose, tras vicisitudes varias, en 1594, bajo la supervisión de Cristóbal Antonelli.

La costosa financiación de la obra corrió a cargo de la ciudad, cediendo Felipe II los diezmos novales que correspondían a la Corona por bula papal de 1569.

La posibilidad de disponer de una mayor seguridad en los riegos y de una mayor abundancia de agua, amplió la superficie cultivada e influyó en la tipología de los cultivos, sobre todo en la expansión del viñedo que, gracias a recibir dos riegos anuales, se convirtió en el cultivo básico de la Huerta y en uno de los soportes del comercio de exportación de la ciudad. Durante el siglo XVII, nuevas roturaciones ampliaron la superficie y se sustituyeron olivares por vides (5). Don Pedro Franqueza, Conde de Villalonga, adquirió tierras de secano para convertirlas en regadío, instaló colonos en ellas y fundó un señorío alfonsino en Villafranqueza, en el límite de la Hiuerta (6).

El agua embalsada se repartió a razón de un minuto por tahulla, concediéndose a los propietarios de tierras en 1565 (7); la regulación del riego

(2) J. ROCA DE TOGORES Y CARRASCO: «Memoria sobre el estado de la agricultura en la Provincia de Alicantre", en Boletín Oficial del Ministerio de Comercio, Instrucción y Obras Públicas, Tomo VI (Madrid 1849), pp. 368-369.

(3) Armando ALBEROLA ROMA: El pantano de Tibi y el sistema de riego en la Huerta de Alicante, Tesina de licenciatura inédita, Facultad de Filosofía y Letras de Alicante, f. 17 .

(4) Ibid. ff. 23-26.

(5) J. CARRERA PUJAL: Historia de la economía española, vol. II, p. 564.

(6) James CASEY: «Irrigació i economía la Paía Valenciá», en Actas del I Congreso de Historia del País Valenciano, IV, pp. 281-289.

(7) J. ROCA DE TOGORES: «Memoria...», p. 370. 
fue reglamentada escrupulosamente en 1669 por la regente Mariana de Austria (8).

Sin embargo, en 1697 el pantano sufrió una rotura y dejó de embalsar agua (9). Las vicisitudes políticas y el alto costo de la reparación impidieron plantear una solución factible hasta 1721. Para entonces las secuelas derivadas de la Guerra de Sucesión comenzaron a superarse: el tráfico marítimo volvió a afluir a la rada y los traumáticos cambios administrativos, políticos y fiscales impuestos tras la toma de la ciudad por los Borbones en 1709 , comenzaron a asentarse. Las nuevas perspectivas que se abrían con la recuperación del comercio portuario estimularon los deseos de reponer la fábrica del pantano y, desde ese año, los capitulares trataron el tema nombrando comisiones y redactando memoriales (10). Al iniciarse la década de los treinta se pasó a una fase de actuaciones más decididas, en la seguridad de que la vida económica de la ciudad había entrado de pleno en una coyuntura favorable que no había que desaprovechar. Si crecía la población, el comercio y los precios, la producción agricola, tan sensible a la expansión económica, no podía quedar rezagada por la falta de agua de riego.

Entre las tareas efectuadas para poner en marcha la reedificiación desiacan las siguientes: la redacción de un memorial al rey sobre la urgencia de la obra; la ejecución de planos y presupuestos, encargándose de ellos los canteros José Terol, Vicente Mingot, Nicolás Puerto, Bautista Asensi y Bautista Borja, constructores de la nueva Casa Consistorial, la portada de Santa María y de la Capilla de la Comunión en la Colegiata de San Nicolás; la recopilación de testimonios de personas destacadas en la vida ciudadana y de labradores huertanos sobre los graves perjuicios que la falta de riego ocasionaba en los cultivos.

Los testimonios recopilados a lo largo de 1731 (11) tienen un doble interés. En primer lugar, se enumeran detalladamente los perjuicios ocasionados en la Huerta desde la rotura, lo que equivale a situar el problema de la reconstrucción de la pared en el nivel de los intereses que la comunidad urbana tenía en las tierras susceptibles de riego con las aguas del embalse; en segundo lugar, la presencia entre los testimonios del de Manuel Martí, Dean de ia Colegial de San Nicolás, y uno de los humanistas españoles con mayor crédito e influencia.

(8) Estatutos para el gobierno de la Ciudad de Alicante concedidos por (...) D. Carlos II, Orihuela 1699, pp. 79-89.

- (9) Rafael VIRAVENS Y PASTOR: Crónica de la ciudad de Alicante, Alicante 1876, p. 150.

(10) Armando Alberola: Op. cir. ff. 35-36.

(11) A.M.A. Lio 22, Expeđiente n. ${ }^{\circ} 22$ : Información fha. a pedimento de esta Iltre. Ciudad de Alicante, sobre los perjuicios que se experimentan en su Huerta y Lugares de ella por la falta de agua para su riego... Año 1731. 
El número de testigos a los que se solicitó informasen sobre los daños ocasionados por la rotura fue de quince. De ellos, siete eran religiosos, los más caracterizados del clero y de las comunidades afincadas en la ciudad: El Dean de la Colegial, el cura más antiguo de la parroquia de Santa María, los curas párrocos de San Juan y Muchamiel, las dos poblaciones huertanas más importantes, y los priores de los conventos de la Orden del Carmen, San Agustín y San Francisco. Dos ricos terratenientes, D. José Paravecino y D. Esteban Rovira, caballeros y destacados cosecheros. Un doctor en medicina, Vicente Guillem, y cinco labradores, uno vecino de Muchamiel y los restantes de San Juan, cuyo testimonio era valorado por tratarse de individuos experimentados. La enumeración de los perjuicios que en la Huerta se producían por la falta de agua, se pueden resumir en seis puntos.

En primer lugar, todos coinciden en que la extensión de la Huerta se había reducido desde 1697, año de la rotura de la pared, y que las vicisitudes bélicas y políticas habían impedido acometer la reparación:

"no se ha podido reedificar por lo calamitoso de los tiempos" (12).

Todos los testimonios mencionan el efecto multiplicador que sobre la superficie cultivada tuvo la construcción de la presa, y cómo, desde la rotura, se habían abandonado tierras y cultuvos:

«de cada día experimenta la Huerta conocido atraso y ruina» (13).

En segundo lugar, manifiestan el evidente deterioro del arbolado y de los viñedos por la falta de agua:

«...que la sequedad acaba sus arboledas y plantados, y en términos que ya no era Huerta sino apariencia de lo que fue» (14).

Las constantes alusiones al descenso de la cosecha de vino reflejan la preocupación por el cultivo más remunerador, ya que las vides regadas daban rendimientos tres y cuatro veces más altos que las de secano; la afirmación de D. Esteban Rovira, importante hacendado y destacado cosechero, es ilustrativa al respecto:

«...por ser uno de los que tienen haciendas en dicha Huerta a quien se le han disminuido también sus cosechas de vino y se le han secado muchísimos árboles» (15).

En tercer lugar, se pone de manifiesto el descenso de habitantes experimentado en el área huertana y las dificultades para el cobro de contribuciones:

«...pues temerosos los vecinos de los apremios militares, y por no poder dar satisfacción suelen desertar muchos con sus familias a otros

(12) Ibid. Testimonio de Fray Francisco Torregrosa.

(13) Ibid. Testimonio de D. Juan Bautista López.

(14) Ibid. Testimonio de Fray Francisco Torregrosa.

(15) Ibid. Testimonio de D. Esteban Rovira y Torres. 
pueblos, abandonando algunas tierras por no sacar de ellas cosa alguna y perder sus trabajos, ocasionado todo de la falta de agua para su riego» (16).

De hecho, la emigración de pobladores de los lugares de la Huerta se debía, más que a la falta de agua, a la presión fiscal que tuvieron que soportar. Las poblaciones de la Huerta se vieron obligadas a mantener durante la Guerra de Sucesión a dos regimientos de caballería y a uno de infantería. Una vez finalizada la contienda, les correspondió mantener una tropa de cincuenta jinetes que quedaron de vigilancia extramuros de la ciudad (17). La obligación de entregar un quintal de forraje por jinete y asistir a la tropa con carne y vino, aunado al deterioro de las cosechas y a las requisas de medios de producción, tan indispensables como cabalgaduras, carros y galeras, fueron motivos más que justificados para que algunos campesinos abandonaran temporalmente la comarca.

El cuarto punto trataba del encarecimiento que sufría la harina al haber quedado inutilizados para la molienda los molinos de la Huerta:

«...ha llegado a extremo que por falta de no correr los molinos, teniendo trigo carecen de harina y verse precisados a buscar, hasta tanto que con el mayor coste y dilación viniese de molinos distantes de otros lugares a causa de que era menester esperar turno para moler, por los muchos que acudian de la jurisdicción de esta ciudad (18).

Efectivamente, la imposibilidad de utilizar los trece molinos harineros existentes en la Huerta suponía un encarecimiento de la harina y un trastorno adicional a los siempre preocupantes problemas del abasto. Los costos de transporte que suponía el envío del grano «por haber de ir a siete o a ocho leguas a moler» (19), fue un problema del que se tenía constancia en el siglo XVII en épocas de sequía, y que los seguiría teniendo tras la puesta en funcionamiento, de nuevo, del embalse. Se acudía a los molinos de Elche o Aspe, o bien se transportaba con pequeñas embarcaciones de cabotaje hasta Altea.

El quinto punto hacía referencia a problemas de salubridad. En opinión de los testigos, el agua detenida, al no correr ésta por los brazales, se corrompía con los calores del verano dando lugar a calenturas pútridas, que eran en realidad tercianas que, como ha señalado Braudel (20), era enfermedad endémica en las llanuras litorales mediterráneas. La Huerta alicantina estuvo azotada durante todo el siglo XVIII por esa enfermedad,

(16) Ibid. Testimonio de Fray Cristóbal Boronat.

(17) A.M.A. Cartas escritas y recibidas, Arm. 11 Lib. 30, f. 173.

(18) A.M.A. Lio 22, Expediente n. ${ }^{\circ} 22$ : Información..., Testimonio de Fray Cristóbal Boronat.

(19) Ibid. Testimonio de D. Manuel Martí.

(20) Fernand BRAUDEL: El Mediterráneo y el mundo mediterráneo en tiempos de Felipe II, Madrid 1976, I, pp. 78-83. 
que también se hallaba presente en las zonas de arrozal del País Valenciano (21), y que los médicos, en el nivel de conocimientos de la época, no acertaban en su etiología. El único testimonio médico del informe, el del doctor Vicente Guillem, señala como causa de la enfermedad el beber aguas estancadas:

«...su contenido es cierto, público y notorio, por haberlo visto el testigo con el motivo de haber pasado con él Don Pedro Ramón ya difunto, de orden de esta Ciudad a la Villa de Muchamiel y demás lugares de la Huerta, a visitar los enfermos que había en el año pasado de mil setecientos veinte y cuatro, y verificó que los que padecían las enfermedades, eran calenturas pútridas y la mayor parte malignas provenidas todas de la corrompida agua que bebian, de manera que las que no las bebieron no las padecieron, y en vista de la experiencia, se mandó con providencia que ninguno bebiese de dha agua, que por ser tan pocas se viciaba con el calor del sol, y que acudiesen a tomarla a una fuente llamada del Juncaret, distante como más de media legua de dha. Villa de Muchamiel, y no pone duda que se experimenta igual efecto los demás veranos, como el agua no sea abundante» (22).

La mayoría de las testificaciones hacen en este punto una referencia a la fuerza que la terciana tomó en 1724 . La fuerte sequía iniciada en 1719 estimuló la expansión de la enfermedad por todo el ámbito huertano, produciéndose algunos fallecimientos y determinando que la ciudad tomara en cabildo medidas precautorias (23).

El sexto y último punto hace referencia a la disminución que sufrían los diezmos a causa del deterioro de los cultivos. Se evidencia, casi sin excepciones, que esta situación perjudicaba tanto a las iglesias como a la Real Hacienda, ya que a esta última le correspondían, por bula de Clemente VIII a Felipe II en 1569, los aumentos diezmales provinientes de la puesta en cultivo de nuevas tierras. Se fijaron unos cotos para la Iglesia situándolos en lo que solian producir los diezmos hasta la edificación de la presa; el monarca cedía los aumentos a la ciudad para que hiciera frente a sus obligaciones con los censales contraídos para la financiación de la obra. Pues bien, los testimonios, en particular de párrocos y religiosos, hacían hincapié en que las cosechas eran tan magras que no se alcanzaban los cotos y que, en consecuencia, los diezmos novales se habían perdido desde la rotura, con el consiguiente perjuicio para el Real Patrimonio:

«...le consta que no llega la parte del Diezmo en mucha disminución al coto que se debe sacar, pues siendo la Huerta de cada día en menos ser por la falta de las aguas, se hace evidente que no puede llegar el caso de percibirse diezmos del augmento" (24).

(21) Mariano y José Luis PESET: Muerte en España. Política y sociedad entre la peste y el cólera, Madrid 1972, pp. 39-100.

(22) A.M.A. Lío 22, Expediente 22: Información..., Testimonio del Dr. Vicente Guillém.

(23) A.M.A. Cabildos, Arm 9 Lib 11, ff. 128 y 133.

(24) A.M.A. Lío 22, Expediente n. ${ }^{\circ}$ 22: Información..., Testimonio de Fray Cristóbal Boronat. 
Esta descripción pesimista sobre los diezmos hay que entenderla, como la totalidad de los testimonios, en plena concordancia con el obligado tono quejumbroso de los escritos. La realidad no era tan sombría como la que se quería mostrar. Una prueba de ello la tenemos en un memorial al rey que en 1739 remitieron los cabildos de la Catedral de Orihuela y de la Colegial de San Nicolás (25), con la pretensión de que se hicieran nuevos cotos antes de que finalizasen las obras de reparación. Aprovechando la presencia en la ciudad del comisionado real Marcelino Ximeno de Samper, regidor de San Felipe, quien trataba de establecer los derechos relativos al Pantano que correspondian al Real Patrimonio, los cabildos eclesiásticos orcelitano y alicantino solicitaron del Rey la cesión de los aumentos diezmales que resultaran de la reedificación. El argumento utilizado para sostener su demanda se basaba en lo obsoleto que habían quedado los cotos fijados a fines del siglo XVI y que la Huerta, pese a los perjuicios causados por la rotura, se habian extendido notablemente. En el convencimiento de que la situación de los cultivos huertanos era mucho mejor que la de 1594, se solicitaba que, al menos, se fijaran nuevos cotos computando los diezmos pagados en los tres años anteriores a 1739.

Queda, por último, referirnos al testimonio del Dean de Alicante, Manuel Martí y cuya transcripción se adjunta al final de esta nota. El interés de su testimonio proviene, más que de los datos que aporta, de la personalidad del testigo y de la excepcionalidad que supone su apoyo a un asunto alejado de sus preocupaciones eruditas e intelectuales.

Sobre la talla de Martí, el trascendental papel jugado por éste en los orígenes de la Ilustración española y su fama en la Europa culta, poco hay que añadir tras los trabajos de Antonio Mestre (26), Luis Gil (27) y Jorge Pérez Durá (28). La lectura de su copiosa correspondencia con Gregorio Mayáns y con Felipe Bolifón, permiten comprender el porqué de nuestro calificativo de excepcionalidad al hallarlo entre los testigos que prestan su testimonio para coadyuvar a la reedificación del pantano. Martí, ciertamente, residió en Alicante desde 1718 sin integrarse en los problemas de la ciudad. Ni un solo papel, informe o testimonio salido de la mano del Dean hemos hallado en los abundantes fondos del Archivo Municipal, pese a la preeminencia de su cargo, a excepción del que comentamos y de las comunicaciones que efectuó a los jurados cuando su nombramiento, ya publica-

(25) Memorial al Rey Nuestro Señor de los Cabildos de la Santa Iglesia Catedral de Orihuela y de la Colegial insigne de Alicante y demás interesados en los Diezmos de su Huerta, Valencia 1799

(26) Antonio MESTRE: Ilustración y reforma de la Iglesia, Valencia 1968.

(27) Luis GIL: «Los apuntes autobiográficos del Dean Martí», en Boletin de la Real Academia Española, LVIII (1978), pp. 47-101.

(28) jorge PEREZ DURA: Epistolado Manuel Martí, Dean de Alicante, y Felipe Bolifón, Alicante 1979. 
das por Vicente Martínez Morellá (29). El fuerte contraste entre la Roma en ebullición intelectual, que había conocido durante largos años Martí, y la incuria alicantina, influyeron en la falta de integración del Dean en su lugar de residencia, donde sólo el Colegio de la Compañía de Jesús reproducía un tipo de cultura que, para desgracia de Martí, se encontraba muy alejada de sus concepciones intelectuales. La opinión emitida por Martí en carta a Mayáns (30) sobre el rector del Colegio, el jesuita Lorenzo López, continuador de la obra de Maltés «Historia de las antigüedades de Alicante», es ilustrativa del afán de Martí por encontrar interlocutores válidos para sus ansias de diálogo erudito y la frustración airada que se producía cuando sus expectativas se venían abajo ante falta de auténticos valores en el contertulio:

«Al P. López no veré, porque para mí es vitando. Recién venido acá travamos amistad, porque me tenían imbuido de grandes excelencias del sugeto. Pulséle, y et inventus est minus habere. Es un hombre erudítulo, con un género de erudición (siento darle este nombre) vulgar y trivial. Jesuítica» (30),

para añadir más tarde:

«...estuvo repetidas vezes a despedirse, pero en vano; porque tenía dado orden en mi casa que no se le abriera la puerta».

La correspondencia con Mayáns o las conversaciones con el napolitano Felipe Bolifón, también con dificultades de integración en la vida ciudadana por su labor de hacer aplicar la nueva fiscalidad castellana tras la Guerra de Sucesión, eran las únicas satisfacciones intelectuales del Dean. Hasta su muerte en 1737 , son frecuentes las quejas de Martí sobre la ignorancia generalizada que le rodea en Alicante:

«...en esta tierra es tal la barbarie, que no hai quien seppa juntar cuatro letras» (32)

«Por el tenor de esta carta y su orthografia, conocerá Vm. el infeliz estado de este ignorante lugar. Y deve $\mathrm{Vm}$. suponer, que me la han dado por el que escrive mejor en Alicante» (33).

Sin embargo, en 1731, cuando la ceguera es ya casi absoluta, admite colaborar con su testimonio en la información que sobre la Huerta efectúa el alcalde mayor de la ciudad. Quizá, este paréntesis a su aislamiento voluntario, esa colaboración con una ciudad en la que se encontraba desarraigado, esté motivada por el afecto que el Dean sentía por la Huerta. En la finca propiedad de los Pascual del Pobil discurrían placenteramente los veranos

(29) Vicente MARTINEZ MORELLA: «Cartas del Dean Martí conservadas en el Archivo Municipal de Alicante», Boletín de la Sociedad Castellonense de Cultura, XLI (1965), II, pp. 113-127.

(30) Antonio MESTRE Epistolario Manyans y Martí, Valencia 1973, p.194.

(31) Ibid. pp. 194-195.

(32) Ibid. p. 403.

(33) Ibid. p. 290. 
del Dean, y la correspondencia que remite durante los meses estivales está signada desde la Huerta:

«hallándome yo en el campo alicantino, a donde me había refugiado para vivir tranquilamente...» (34).

Los momentos felices de Martí en una tierra que no le comprendía son, precisamente, aquellos que pasa en la Huerta, cuando habla de las cosas del agro (35) o cuando canta las excelencias de la quinta de Pobil (36). Por ello, en la defensa de un campo querido que se deteriora por la falta de agua es donde hay que encontrar la razón del testimonio de Manuel Martí en favor de la reconstrucción del Pantano de Tibi.

\section{Testimonio de D. Manuel Martí sobre los perjuicios que se experimentan en su Huerta y Lugares de ella por la falta de agua para su riego, ocasionada de no estar compuesto el Pantano construido en el término de la Villa de Tibi.}

En la Ciudad de Alicante en dichos día, mes y año, Joseph Cazorla Pror. de causas del Juzgado Real de esta Iltre. Ciudad y en su nombre, para la información que tiene ofrecida y le está mandada dar, presentó por testigo a Don Manuel Martí, Dr. en Sagrada Teología y Canónigo, Dignidad de Dean, de la Insigne Iglesia Colegial del Señor San Nicolás de la misma ciudad, del qual yo el Essno. usando de la comisión que por el auto antecedente me está concedida, recibi juramento, y el sussodho lo hizo tacto pectore more sacerdotali, baxo cuyo cargo ofrezió dezir verdad sobre lo que fuere preguntado; y haviéndolo sido el thenor de la petición que va por cabeza, y sus capítulos, respondió lo que sigue:

Primeramente, preguntado sobre lo relacionado en dha Petición Dixo, que es cierto todo su contenido, excepto lo que se expresa de que por falta de medios no se ha reparado la ruina del Pantano, por quanto el que atestigua no lo sabe, ni puede dezir; y sólo si en razón de los demás le consta, esto es, por lo que mira a las aguas vivas que se refiere el pedimiento, por ser público y notorio el que la Ciudad las tiene compradas y que actualmente está siguiendo pleito sobre ello contra los usurpadores de dhas aguas; en lo que mira a la construcción y fábrica de dho Pantano, lo sabe higualmente,

(34) Ibid., p. 40.

(35) Fco. Jorge PEREZ DURA: Epistolario..., pp. 61-63.

(36) Ibid., pp 84-87: «Corre cerca un riachuelo muy agradable, por Hércules, con el suave murmullo del agua que se desliza, aunque, no obstante, éste no es perenne ni tampoco fluye constantemente, ya que solamente discurre en los días establecidos, evidentemente para el reigo de los campos. Con lo cual ocurre que aquel maná tanto más querido cuanto que más deseado (...). Finalmente, a cualquier parte que miro, todas las cosas son alegres, encantadoras, verdeantes»). 
assí por ser público y notorio, como por haverlo ohido dezir a muchas personas de distinción, y las tales personas haver visto papeles e instrumentos tocantes a dha fábrica, su coste y facultades que para ello huvo; y sobre la rotura o brecha que hoy tiene, por ser también público y común opinión en esta Ciudad; y últimamente en razón de coste que puede importar su reparo ha ohido también dezir que sería cosa de hasta unos diez y seis a diez y siette mil pesos, con lo qual se pudiera remediar dicho daño, y por consiguiente los grandes perjuhicios que se han experimentado en la Huerta desde que se hizo en el Pantano dicha rotura, pues por la falta de agua ha ha padezido, y padeze, se halla tan deteriorado, que apenas puede llamarse Huerta y responde:

1.- «Preguntado, en razón de lo contenido en el primer capítulo; Dixo que también es cierto lo que en él se expresa, y lo sabe el testigo, por haverlo ohido dezir a muchas personas prácticas, ancianas e intelixentes en las tierras de dicha Huerta, las que le han assegurado ser oy las tierras de dicha Huerta que regava el agua de dicho Pantano, dobladas, de las que se componía antes de su construcción y primitivo estado, y responde:

2.- Preguntado sobre lo que contiene el segundo capítulo; Dixo, el higualmente cierto, lo que en él se refiere. Y lo sabe el testigo por ser como es público y notorio en esta Ciudad, y por la falta de agua que queda referi$\mathrm{da}$, y responde:

3.- Preguntado sobre lo que se refiere al tercer capítulo; Dixo ser cierta la pobreza de los vezinos que se refiere por la falta de cosechas que en él se menciona, como también el ceder en notable daño de los Reales Intereses por la difucultad que se experimenta en la cobranza de las contribuciones; y en prueba de ello añade el testigo le consta de que muchos vezinos de los Lugares de la Huerta han abandonado sus casas y se han ido a vivir a otras partes, $y$ responde:

4.- Preguntado en razón de lo contenido en el Quarto capítulo, dixo ser cierto cuanto en él se expresa, y añade que el daño que recibe el Público de no correr los molinos la mayor parte del año, por la falta de agua, pues de esto nace el aumento del precio de la harina, por haber de ir a siete o a ocho leguas a moler, se sigue otro, y es el deservicio de Su Mag. por ser esta una Plaza de Armas tan importante, y en donde tiene su guarnición continua a cuya manutención importa tanto tener los molinos inmediatos, y responde:

5.- Preguntado sobre el contenido del quinto capítulo, Dixo: Que también es cierto que para el gasto de las casas de dicha Huerta, no tienen otra agua que la que viene a ella; y faltando esta enteramente (como falta todos los veranos) y secándose todas las azequias por donde suele correr, y quedando solamente rebalsada en algunas partes en corta cantidad, se ven precisados los pueblos que habitan en dha Huerta a bever de ella, corrompida y hedionda, con peligro inminente de que se encienda una peste, como 
en efecto siette años ha, a ocho, fue tal la epidemia de enfermedades que sucedió en dhos Lugares que se dudó si era contagio; todo lo que expone el que atestigua, como testigo de vista, por haver passado dichos veranos en la Huerta y haver visto también con lástima y commisseración el infeliz y calamitoso estado de aquellos Pueblos, y responde:

6.- Y últimamente, preguntado por el sexto y último capítulo, Dixo ser cierto que desde que está derrumbado el Pantano no ay augmento de Diezmos para Su Mag., pues estos los perciben por entero las Iglesias, lo que no sucedía quando estava el dicho Pantano entero, pues éstas sólo percibían una cierta cantidad de granos que llamavan cotto port haberse assí establecido en los principios de su fundación; y que todo lo que lleva depuesto es público y notorio, pública voz y fama y común opinión en esta Ciudad y Lugares de ella, sin que el testigo haya sabido, ohido ni entendido cosa en contrario; y que es la verdad que declara, en cargo del Juramento que tiene hecho, y que es de edad de sessenta y ocho años, poco más o menos, y lo firmó que doy fee.- Dr. D. Manuel Martí.- Ante mí, Adrián Cazorla.

(A.M.A. Lio 22, Expediente 22, ff. 5-8.) 